\title{
Prevalence of Diarrhea and Associated Risk Factors Among Children Under-Five Years of Age in Nigeria
}

\author{
Bodunwa, O. K. Aladeniyi O. B. Patrick O. A. \\ Federal University of Technology Akure
}

\begin{abstract}
Diarrhea is the second leading cause of under-five child mortality after pneumonia. The absence of clean water source, essential sanitation and hygiene is responsible for almost $88 \%$ of the disease burden in the Nigeria. This study aimed to identify the risk factors for the occurrence of childhood diarrhea among children aged between 0 5 years in Nigeria. Nigeria Demographic and health survey (NDHS) data for year 2013 was used for the purpose of this study. Descriptive Statistics was used to identify the mean age of the mother, children and also the frequencies and percentage of the independent factors. Multilevel Probit Regression was computed to assess the independent factors of childhood diarrhea. Two-way table with measures of association was used to test the association of the predictor variables. The prevalence of diarrhea in the two weeks period among under- five children in Nigeria is $9.52 \%$. The result showed that maternal/mother's education attainment, region, sex of children, maternal/mother's age, children's age, source of water, place of residence, breast feeding status, family Income and mass media were found to be positively associated risk factors for childhood diarrhea.
\end{abstract}

Keywords: Prevalence, Diarrhea, Risk factor, Probit Regression, Children, Mother/care givers.

DOI: $10.7176 / \mathrm{JAAS} / 60-05$

Publication date: January $31^{\text {st }} 2020$

Introduction: As defined by World Health Organization diarrhea is the passage of three or more loose or liquid stools per day, or more frequently than normal for the individual. It is usually a symptom of gastrointestinal infection, which can be caused by a variety of bacterial, viral and parasitic organisms. Severe diarrhea leads to fluid loss, and may be life threatening, particularly in young children and people who are malnourished or have impaired immunity (WHO bulletin, 2013).

Globally, as many as 800,000 children die each year from diarrhea, with most deaths occurring in developing countries (Bhutta, 2013). Daily Nigeria loses about 2,300 under-five children ranking the country as the second largest contributor the under-five diarrhea. The Millennium Development Goals recognize child health and survival as an important socio development issue. It is estimated that one in ten children dies before the first birthday, and one in five before their fifth birthday (UNICEF, 2016).

Diarrhea is still responsible for high rates of mortality in children worldwide. Reducing child mortality is the 4th of the United Nations Millennium Development Goals (MDGs).

In Salvador, a city in north-eastern Brazil, a study was conducted on a hierarchical model for studying risk factors for childhood diarrhea by Ferrer S. R. (2008). Results were that "socioeconomic factors contributed most to determining diarrhea occurrence, followed by interpersonal contact, while factors related to food". The findings were concluded to have interpersonal contact to be the highest factor on the hierarchical levels.

The absence of clean water source, essential sanitation and hygiene is responsible for almost $88 \%$ of the disease burden in the Nigeria. According to statistics by (WHO bulletin, 2013), children under three years of age in developing countries experience on average about three episodes of diarrhea every year. Hence, the purpose of this study is to assess the factors associated with childhood diarrhea using a large sample size from across sectional descriptive survey. This gives high power to the results obtained from the study because of the sample size, (Rowe, 2008).

Material \& Method: The design used in this study is a secondary analysis of data from Nigeria Demographic and Health Survey (NDHS) 2013, which is a nationally representative, cross sectional descriptive survey that covered the entire population residing in non-institutional dwelling units in the country. Data analysis was done using Stata version 13.0 SE (Stata Corporation, college station, Texas). However descriptive statistics were used to summarize the study variables. The analyzed information was then summarized using tables. The primary outcome variable was the reported occurrence of diarrhea, if the child had diarrhea in the last two weeks including the last 24 hours prior to data collection time or not. The 11 independent variables included in the study were identified from a literature review conducted earlier and associated with the occurrence of diarrhea episodes among children under five years of age. They included: respondents age group, respondents' educational attainment, place residence, wealth index, and sex of child, age of child, sources of drinking water, type of toilet facility, breastfeeding status and mass media. 
Association of children's socio-economic factors and diarrhea

Table 1.0: Association of children's socio-economic factors and diarrhea

\begin{tabular}{lllll}
\multicolumn{5}{l}{ Table 1.0: Association of children's socio-economic factors and diarrhea } \\
Variables & & $\begin{array}{c}\text { Diarrhea } \\
\text { No no (\%) }\end{array}$ & Yes no (\%) & P-Value \\
\hline Sex & Male & $10,799(90.35)$ & $1,153(9.65)$ & $0.651^{* *}$ \\
& Female & $11,148(90.52)$ & $1,167(9.47)$ & \\
Age group & $0-11$ & $4,210(88.11)$ & $568(11.89)$ & $0.000^{* *}$ \\
& $12-23$ & $3,703(83.48)$ & $733(16.52)$ & \\
& $24-35$ & $3,532(88.33)$ & $470(11.74)$ & \\
& $36-47$ & $3,813(92.44)$ & $312(7.56)$ & \\
Breast & $48-59$ & $3,743(94.76)$ & $207(5.24)$ & \\
Status & & & & $0.000^{* *}$ \\
\hline
\end{tabular}

**Chi-square Test

From the analysis, the child's age group and breast feeding status were significant at $95 \% \mathrm{CI}$, while sex male was not significant (p-0.651) at 95\% CI. It indicated that there is a strong association between the occurrence of childhood diarrhea to age and currently breast feeding while, we conclude that there is no association between occurrence of childhood diarrhea and sex of the child.

Environmental factors associated with diarrhea

Table 1.1: Association of environmental factors and diarrhea

\begin{tabular}{|c|c|c|c|c|}
\hline \multirow[b]{2}{*}{ Variables } & \multicolumn{3}{|c|}{ Diarrhea } & \multirow[b]{2}{*}{ P-Value } \\
\hline & & No no $(\%)$ & Yes no $(\%)$ & \\
\hline \multirow[t]{2}{*}{ Water Source } & Protected & $9.190(89.19)$ & $1,206(8.64)$ & $0.000 * *$ \\
\hline & Unprotected & $12,757(91.36)$ & $1,114(10.81)$ & \\
\hline \multirow[t]{2}{*}{ Toilet Facility } & Improved & $12,137(90.46)$ & $1,280(9.54)$ & $0.905 * *$ \\
\hline & Unimproved & $9.810(90.41)$ & $1,040(9.96)$ & \\
\hline \multirow[t]{2}{*}{ Residence } & Urban & $6,891(91.33)$ & $654(8.67)$ & $0.001 * *$ \\
\hline & Rural & $15,056(90.04)$ & $1,666(9.96)$ & \\
\hline \multirow[t]{3}{*}{ Mass Media } & Radio & $12,880(91.92)$ & $1,148(8.18)$ & $0.000 * *$ \\
\hline & Television & $9,780(92.58)$ & $784(7.42)$ & \\
\hline & Newspaper & $2,978(93.47)$ & $208(6.53)$ & \\
\hline
\end{tabular}

**Chi-square Test

From the analysis in above variables such as water source ( $p$-value 0.000 ), place of residence (p-value 0.001 ), mass media (p-value 0.000) were significant at 95\% CI which indicated that there is a strong association between the occurrence of childhood diarrhea and mass media. While, toilet facility ( $p$-value 0.905 ) is not significant at $95 \%$ $\mathrm{CI}$ and conclude that there is no association between the occurrence of childhood diarrhea and toilet facility.

For Table 1.2, All the variables (age, region, education attainment, wealth index) in this category were found to be significant at 95\% during the analysis, age (p-value 0.000), wealth index (p-value 0.000), region (p-value $0.000)$ and mother's education attainment (p-value 0.000). It indicated that there is a strong association between the occurrence of childhood diarrhea and each of the selected factors for the mother. 
Association of mother's socio-demographics and diarrhea

Table 1.2: Association of Mother's socio-economic factors and diarrhea

\begin{tabular}{|c|c|c|c|c|}
\hline & & arrhea & & \\
\hline Variables & & No no $(\%)$ & Yes no $(\%)$ & P-Value \\
\hline & Poorest & $4,980(87.99)$ & $680(12.01)$ & $0.000 * *$ \\
\hline & Poorer & $5,245(88.79)$ & $662(11.21)$ & \\
\hline Wealth Index & Middle & $4,513(91.15)$ & $438(8.85)$ & \\
\hline & Richer & $4,107(92.56)$ & $330(7.44)$ & \\
\hline & Richest & $3,102(93.66)$ & $210(6.34)$ & \\
\hline & No Education & $10,066(88.82)$ & $1,267(16.18)$ & $0.000 * *$ \\
\hline Mothers' & & & & \\
\hline Education & Primary & $4,692(90.88)$ & $471(9.12)$ & \\
\hline & Secondary & $6,053(92.23)$ & $510(7.77)$ & \\
\hline & Higher & $1,136(94.04)$ & $72(5.96)$ & \\
\hline & $<20$ & $1,039(87.38)$ & $150(12.62)$ & $0.000 * *$ \\
\hline Mothers' & $20-24$ & $4,231(90.88)$ & $509(10.74)$ & \\
\hline Categories & $25-29$ & $6,121(90.52)$ & $641(9.48)$ & \\
\hline & $30-34$ & $4,788(91.01)$ & 473(8.99) & \\
\hline & $>35$ & $5,768(91.34)$ & $547(8.66)$ & \\
\hline & NorthCentral & $3,431(93.64)$ & $233(6.36)$ & $0.000 * *$ \\
\hline & North East & $4,313(80.41)$ & $1,051(19.59)$ & \\
\hline & North West & $6,362(92.22)$ & $537(7.78)$ & \\
\hline & South East & $2,165(91.58)$ & $199(8.42)$ & \\
\hline Regions & South South & $2,674(96.29)$ & $103(3.71)$ & \\
\hline & South West & $3,002(93.84)$ & $197(6.16)$ & \\
\hline
\end{tabular}

**Chi-square Test

\section{Result \& Discussion:}

This study reveals that overall prevalence of diarrhea in Nigeria is about $9.56 \%$. In the north central region, the two weeks period prevalence of diarrhea was $6.36 \%$, diarrhea was prevalent in north east with $19.59 \%$. Diarrhea was prevalent among children aged (12-23) months with $16.52 \%$. it showed that children aged $12-23$ months are more likely a risk factor of childhood diarrhea in Nigeria. Prevalence of diarrhea showed no much difference between male and female children (9.65\% in males and $9.47 \%$ in females). Diarrhea was noted to be $10.69 \%$ in currently breastfed children. Currently breast feeding children were less likely to have diarrhea.

Mothers who were in the urban areas with prevalence $8.67 \%$ was significantly different with ( $p$-value $<0.05$ ) having diarrhea compared to those in the rural areas with prevalence $9.99 \%$. Mother's educational level was found to have a strong association with diarrhea with highest prevalence rate of $16.18 \%$ among no education category. Mother's educational level was found to have a strong association with diarrhea with highest prevalence rate of $16.18 \%$ among no education category. Also rural areas had higher prevalence of diarrhea $9.96 \%$ compared to those in the urban area with prevalence rate $8.67 \%$ because water sources, droughts and sanitation in the rural were worse than in the urban areas. Wealth index was significant at chi-square test (p-value 0.000). However, childhood diarrhea was most prevalent among the category of wealth index poorest with $12.01 \%$. The study revealed that maternal age groups had strong association with diarrhea in children using chi-square analysis ( $p$-value 0.000$)$.

\section{Conclusion:}

This study has identified some important risk factors that showed strong association with diarrhea among children under the age of five which include socio-economic factors for mothers and children as well as environmental factors. The factors associated with diarrhea among under-five children were found to be children's age, mother's age, region, educational attainment, place of residence, wealth index, breastfeeding status, water source and mass media.

\section{References}

Bhutta, A. Z. (2013). Global burden of childhood diarrhea and pneumonia. What can and should be done? Global health. doi:10.1542/peds.2012-3737.

Ferrer, S. R. (2008). A hierararchical model for studying risk factors for childhood diarrhea: a case-controlstudy in a middle-income country. International Journal of Epidermiology 2008, 37, 805-815. 
Rowe (2008). A hierarchical model for studying risk factors for childhood diarrhea: a case-controlstudy in a middle-income country. Journal of Epidemiology, 37, 805-815.

UNICEF. (2009). World Health Organization. Diarrhoea: why children are still dying and what can be done. New York: UNICEF, World Health Organization, 2009.

UNICEF. (2016). The world has missed the MDG sanitation target by almost 700 million 2016 Jan. Retrieved Feburary 24, 2017, from https://data.unicef.org/topic/water-andsanitation/

WHO bulletin.(2013). Estimating child mortality due to diarrhea in developing countries. Retrieved April 9, 2015, from http://www.who.int/bulletin/volumes/89/9/07-050054/en/index.html 